\title{
Técnicas de Hidroterapia em um caso de Jarcho-Levin
}

\author{
Hydrotherapy techniques in a case of Jarcho-Levin
}

\section{Lílian de Fátima Dornelas ${ }^{1}$}

\section{RESUMO}

Objetivo. O presente estudo tem como objetivo analisar os efeitos das técnicas de hidroterapia na amplitude de movimento, força muscular e na independência funcional em um paciente com síndrome Jarcho-Levin após uma cirurgia corretiva da coluna vertebral. Método. Um indivíduo foi submetido a 48 sessóes abrangendo os métodos Watsu, Hidrocinesioterapia e Halliwick durante 4 meses. A avaliação pré e pós-tratamento consistiram no exame clínico e na aplicação de questionário sobre independência funcional. Resultados. Obteve-se ganho nas medidas de amplitude de movimento e força muscular em membros inferiores e na independência nas trocas posturais e nas Atividades da Vida Diária (AVDs) pelo questionário da Medida de independência funcional (MIF). Conclusáo. As técnicas de hidroterapia mostraram-se benéficas, neste estudo de caso, em relaçáo a ganho de amplitude de movimento, força muscular e nos domínios de banho, vestiário, transferências e locomoção pela MIF.

Unitermos. Jarcho-Levin, Hidroterapia, Coluna Vertebral.

Citaçáo. Dornelas LF. Técnicas de Hidroterapia em um caso de Jarcho-Levin.

\begin{abstract}
Objective. This study aims to analyze the effects of hydrotherapy techniques on range of motion, muscle strength and functional independence in a patient with Jarcho-Levin syndrome after corrective surgery of the spine. Method. One individual was subjected to 48 sessions covering procedures Watsu, and Hydrokinesioterapy, Halliwick for 4 months. The evaluation pre and post-treatment consisted of clinical examination and questionnaire on functional independence. Results. We obtained gain in measures of range of motion and muscle strength in lower limbs and postural changes in independence and the AVD questionnaire functional independence measure (MIF). Conclusion. The techniques of hydrotherapy shown to be beneficial in this case study, for the gain range of motion, muscle strength and areas of bathing, dressing, transfers and locomotion by MIF. Keywords. Jarcho-Levin, Hydrotherapy, Spine.
\end{abstract}

Keywords. Jarcho-Levin, Hydrotherapy, Spine.

Citation. Dornelas LF. Hydrotherapy techniques in a case of Jarcho-Levin.

Trabalho realizado na Associaçáo de Assistência à Criança Deficiente Uberlândia-MG, Brasil.

1. Fisioterapeuta, Mestre em Ciências da Saúde, Doutoranda em Ciências da Reabilitação da Escola de Educação Física, Fisioterapia e Terapia Ocupa-

Endereço para correspondência: Rua Mário Segatto, 297, Segismundo Pereira CEP 38408-741, Uberlândia-MG, Brasil.

E-mail: liliandefatima@hotmail.com cional - UFMG, Belo Horizonte-MG, Brasil. 


\section{INTRODUÇÃO}

A síndrome de Jarcho-Levin é uma desordem genética rara ocasionada por um padrão de herança autossômica recessiva. Foi descrita pela primeira vez em 1938 por Saul Jarcho e Paul M. Levin, em dois irmãos com malformaçóes múltiplas vertebrais. Estima-se no mundo, uma frequência de 0,2 por 100.000 nasci$\operatorname{dos}^{1-3}$.

Esta síndrome caracteriza-se por malformaçóes das vértebras e das costelas, com dificuldade na ventilação. $\mathrm{O}$ tronco destes indivíduos apresenta-se curto devido à fusão de várias vértebras, hemivértebras e fusão das costelas. Anomalias de vértebras cervicais podem causar um curto pescoço e circulação limitada, e uma baixa implantaçáo dos cabelos. Em muitos casos, o abdômen, braços e pernas podem ser anormalmente longos $^{1-3}$.

Os bebês nascidos com Jarcho-Levin podem crescer saudáveis e levar uma vida normal, no entanto, ao longo dos anos, a tendência destes indivíduos é serem submetidos a cirurgias na coluna com o intuito de acolher melhor os crescentes pulmóes ${ }^{1-3}$.

Tratar estes pacientes severamente comprometidos tem sido um desafio para a fisioterapia, uma vez que estes indivíduos apresentam deformidades importantes que dificultam a realização de manuseios em solo ${ }^{3}$. Contudo, uma modalidade que tem sido bem aceita pelos pacientes e recomendada pelos profissionais da área é a hidroterapia.

A hidroterapia é aplicada em uma piscina aquecida, através da utilizaçáo de técnicas especialmente desenvolvidas com objetivos de promover e manter a saúde, tratar e reabilitar indivíduos com distúrbios funcionais. O benefício da água está principalmente no princípio físico chamado empuxo, pois é devido à açáo dele que ocorre o alívio do estresse sobre as articulaçóes sustentadoras de peso e permite que se realize movimento em forças gravitacionais reduzidas, dessa forma, as atividades que não sustentam peso podem ser iniciadas antes mesmo de serem possíveis no solo. Além disto, os efeitos fisiológicos dos exercícios combinados com os demais princípios físicos da água acrescentam- se nas vantagens da atividade neste meio ${ }^{4,5}$.

Em vista dos fatores apresentados acima, o objetivo deste estudo é analisar os efeitos das técnicas de hidroterapia sobre um indivíduo com síndrome de Jarcho-Levin após uma cirurgia corretiva da coluna vertebral.

\section{MÉTODO}

Paciente feminina, 23 anos de idade com o diagnóstico de Síndrome de Jarcho-Levin, com independência nas Atividades da Vida Diária (AVD's) e nas Atividades de Vida Profissional (AVP's). Foi submetida em abril de 2008 (com 22 anos de idade) a uma cirurgia corretiva (escoliose). Após, relatou perda de força esfincteriana (desejo e inibição miccional ausente), de sensibilidade da cintura até os pés, de força muscular e de Amplitude de Movimento (ADM), algia na coluna e dependência em todas as AVDs. Em casa, ficou acamada somente na postura supina com dificuldades nas trocas posturais baixas/altas e transferências. Segundo relatório médico evoluiu para uma paraplegia (devido isquemia na medula na regiáo torácica).

A avaliação pré e pós tratamento consistiu de exame clínico: (ADM ativa) por goniometria, Força Muscular e sensibilidade pela escala de ASIA, Tônus Muscular pela Escala de Ashworth Modificada e a aplicação do questionário Medida de Independência Funcional (MIF) nos domínios: banho, vestiário, transferência e locomoção.

Foi realizado hidroterapia em piscina aquecida (340) na AACD/MG, 3 vezes por semana de 40 minutos cada sessão. $\mathrm{O}$ atendimento com a paciente foi realizado por uma terapeuta experiente em hidroterapia e as sessões foram individualizadas. Foram realizadas reavaliaçóes mensais pela terapeuta.

Foram aplicadas as técnicas: Watsu, Halliwick e Hidrocinesioterapia. O método Watsu foi criado na década de 80 nos Estados Unidos por Harold Dull. É um método que tem como base alongamentos executados no Zen Shiatsu com o objetivo de reeducação muscular, ventilação e relaxamento ${ }^{6}$. A técnica Halliwick foi desenvolvida por volta da década de 50, em Londres 
por James MacMilan. Baseia-se nos princípios científicos da hidrodinâmica e da mecânica corporal, que, por meio da qual, propóe a independência no meio líquido ${ }^{7}$. E por fim, a Hidrocinesioterapia que é a base de todos os métodos e tem como fundamento a teoria do controle motor. Esta técnica pode ser definida como um conjunto construído de procedimentos, modalidades e condiçóes aplicados individualmente no meio líquido com o objetivo de promover a manutenção e/ ou melhora da capacidade funcional do paciente ${ }^{8}$.

O emprego das técnicas utilizadas foi de acordo com os objetivos traçados. O objetivo a curto prazo foi o de otimizar a independência das trocas posturais/ transferências para as AVDs, alívio de dor; amplitude movimento/força muscular em tronco/membros superiores e inferiores e exercícios ventilatórios. $\mathrm{E}$, a longo prazo, marcha domiciliar com apoio.

O método de avaliação e tratamento empregados nesta pesquisa baseou-se em estudos na área de terapia aquática que envolve a utilização de exames clínicos (ADM/Força muscular) e de testes funcionais ${ }^{7}$. Segundo Noh et al. ${ }^{7}$, ao avaliar o efeito da terapia aquática na promoção do controle e força muscular de tronco em pacientes com problemas de coluna, foi realizada a aplicação de teste de força muscular e a escala de equilíbrio de Berg, e, as técnicas Ai Chi e Halliwick como intervenção. E, após o período do tratamento (8 semanas), concluiu-se que, os indivíduos obtiveram melhora significativa (aumento de força muscular e do equilíbrio de tronco), sendo positiva a associação de técnicas hidroterápicas, como também o método que os indivíduos foram avaliados, pois, pode-se verificar mudanças tanto quantitativa como qualitativa.

O estudo de caso foi aprovado pelo Comitê de Ética em Pesquisa da AACD/SP n ${ }^{\circ}$ 12/2009.

\section{RESULTADOS}

No pré tratamento, a MIF acusou o valor de $57,1 \%$, sendo que, as pontuações mais baixas foram nas atividades básicas do dia a dia (banho, vestiário, transferências e locomoção), e, no exame clínico, foram obtidos os valores de: Amplitude de Movimento
(ADM - ativa) por goniometria: $75^{\circ}$ e $55^{\circ}$ em flexo dos quadris/joelhos, respectivamente; Grau 2 em membros inferiores de Tônus Muscular pela Escala de Ashworth Modificada; Alteração da sensibilidade (grau 1) e Força Muscular (grau 2 nos principais grupos musculares dos membros inferiores), segundo a escala ASIA; Algia na coluna $(4+/ 5+)$.

Nas primeiras sessóes, a hidroterapia priorizou o alívio de dor, uma vez que era o fator que limitava a paciente para as demais atividades. As sessóes eram baseadas na técnica de Watsu com o intuito de promover relaxamento, reeducação muscular e ventilação, através de alongamentos executados no Zen Shiatsu. Assim, após 15 sessōes, foi reaplicado a MIF e a paciente obteve uma melhora significativa, passando a pontuar $62,7 \%$ (pontuando mais em relação às transferências e auxiliando mais no vestiário). Apresentou diminuição da dor $(2+/ 5+)$ que a possibilitou realizar de forma independente em solo as trocas posturais baixas (mudanças de decúbito) e começou a ficar sentada com apoio por 10 minutos.

Após a $15^{\text {a }}$ sessão, acrescentou-se à terapia atividades hidrocinesioterápicas que compreendiam: alongamentos e estímulo à movimentação ativa (utilizando os princípios da água como a viscosidade) para a coluna/membros superiores e inferiores. Proporcionaramse posturas no meio líquido que em solo não era possível por um tempo maior, tais como, a postura sentada e em ortostase. Assim, observou-se na $30^{\text {a }}$ sessão que a paciente conseguiu transferir o aprendizado da água para o solo, permanecendo sentada por maior tempo (30 minutos) e ficando na postura ortostática em casa. As dores já não eram mais suas queixas principais e sim, o retorno à marcha.

Completando o primeiro trimestre de terapia (36 sessōes), o objetivo da hidroterapia passou a ser a deambulação com apoio de forma domiciliar, uma vez que a paciente agora permanecia diurnamente em cadeira de rodas e somente alguns momentos em pé. Optou-se por realizar Halliwick, que se baseia em princípios científicos da hidrodinâmica e da mecânica corporal, que, por meio da qual, propóe a independência 
no meio líquido. Foram feitas atividades rotacionais, ventilatórias e deslocamentos na água e após a 48a sessão, a paciente conseguiu deambular no meio líquido sem auxílio (nível da água: mamilos) e nados adaptados com mergulhos de 30 segundos. Em solo, passou a transferir-se sozinha da cadeira de rodas para a cama e vice-versa, da postura sentada (mantendo por mais de 30 minutos nesta postura) para a ortostase com auxílio de andador e, com a ajuda deste, iniciou a marcha em casa.

Aos quatro meses de terapia aquática (48 sessões), foi feita a avaliação pós tratamento e a paciente apresentou melhora da ADM ativa em membros inferiores (flexo de quadris $\left(10^{\circ}\right)$ e joelhos $\left(5^{\circ}\right)$ ); Aumento da força muscular (grau 4) nos principais grupos dos membros inferiores com retorno da sensibilidade (grau 2), pela escala ASIA; Diminuição significativa da dor na coluna $(1+/ 5+)$. E, na reaplicação da MIF foi obtido o valor de $75,7 \%$ com melhora significativa nos domínios que haviam tido pontuação mais baixa no pré-tratamento (Tabela 1).

\section{DISCUSSÃO}

A terapia aquática é indicada para diversas doenças, e dentre elas, àquelas em que os pacientes apresentam dor que limita realizar as funçôes do dia a dia. Para estes pacientes, o ambiente aquático proporciona estimulação sensorial global, e, somado ao efeito da temperatura, permite manuseios que corroboram para o alívio da dor de forma mais precisa que em solo. Além disso, acessa e redireciona as fontes restantes disponí- veis para atingir a recuperação máxima. $\mathrm{O}$ tratamento estimula a reação sem sobrecarregar o sistema danificado e minimiza as respostas anormais ${ }^{4,5}$. $\mathrm{O}$ que foi visto no presente estudo, uma vez que a paciente permitiu ser manuseada desde as primeiras sessóes mesmo com algia importante na coluna.

$\mathrm{Na}$ água é muito mais fácil estimular, pois é um meio tridimensional que possibilita ao indivíduo controlar ativamente seu corpo em diferentes posiçóes. Esta vantagem favorece o caminho da plasticidade neuromuscular, pois proporciona diferentes formas de aprendizado. $\mathrm{O}$ aprendizado no meio líquido facilita, motiva e ajusta as habilidades motoras do indivíduo e torna-se eficaz quando há transferência para o meio terrestre $^{4,5}$. No presente estudo, o meio líquido proporcionou posturas que em solo seria impossível de se realizar de forma precoce.

Nos estudos de terapia aquática, não há achados que comprovem qual a melhor técnica para cada tipo de patologia. Waller, Lambeck e Daly $(2008)^{9}$ realizaram uma revisão sistemática no intuito de conhecer quais os tipos de terapia aquática são eficazes no tratamento da dor lombar, e, dentre os estudos selecionados, foi visto que todas as técnicas foram benéficas, no entanto, não foi encontrado nenhuma intervenção que fosse superior às demais. Assim, no presente estudo foi visto que o mais importante não é se preocupar com a melhor técnica e sim saber fazer o uso de cada uma no momento oportuno?.

A técnica Watsu foi optada primeiramente em virtude do que ela proporciona e do que a paciente

Tabela 1

Valores dos dominios avaliados no questionário de Medida da Independência Funcional

\begin{tabular}{lrr}
\hline \multicolumn{1}{c}{ MIF } & \multicolumn{2}{c}{ TRATAMENTO } \\
\hline Domínios & PRÉ & PÓS \\
\hline Banho & ${ }^{*} 1$ & ${ }^{* * * 5}$ \\
Vestir parte superior do corpo & ${ }^{*} 2$ & ${ }^{* * * * *}$ \\
Vestir parte inferior do corpo & 1 & $* * * 6$ \\
Transferências & 1 & 6 \\
Locomoção & 1 & 5 \\
\hline
\end{tabular}

* Auxílio total;** Auxílio máximo; ${ }^{* * *}$ Supervisão ou preparação; ${ }^{* * * *}$ Independência modificada; ${ }^{* * * * *}$ Independência completa 
apresentou inicialmente. Este método que tem como base alongamentos executados no Zen Shiatsu possibilitou relaxamento e reeducação ventilatória e consequentemente, alívio da dor. Posteriormente, o uso da Hidrocinesioterapia contribuiu para a melhora da capacidade funcional da paciente, tais como, trocas posturais, ADM e força muscular. Acrescentou-se logo após, a técnica Halliwick, pois, propóe a independência no meio líquido e, foi fundamental, uma vez que motivou e encorajou a paciente que almejava voltar a andar ${ }^{6-9}$.

Um dos grandes desafios da terapia aquática é demonstrar os ganhos funcionais da água para o solo. Contudo, a qualidade da transferência da aprendizagem motora na água para o solo depende da semelhança entre as duas tarefas ou entre os dois ambientes $\mathrm{e}$ que, quanto mais às demandas do ambiente da prática se assemelharem às do ambiente real, melhor será a transferência ${ }^{4}$. Foi visto que ao preconizar tarefas funcionais no meio líquido com a paciente por meio da hidrocinesioterapia, tais como: realizar mudanças de decúbito, ficar sentada e andar, houve transferência positiva deste aprendizado feito na água para o solo em poucas sessóes ${ }^{10}$.

\section{CONCLUSÃO}

As técnicas de hidroterapia mostraram-se bené- ficas neste estudo de caso em relação a ganho de amplitude de movimento, força muscular e, principalmente, nas atividades funcionais tais como: banho, vestiário, transferências e locomoção. Além disso, a seleçáo da técnica no momento oportuno facilitou o alcance do objetivo proposto.

\section{REFERÊNCIAS}

1.Umphred D. A. Reabilitação Neurológica, São Paulo: Manole, 2004, 540p. 2.Rowland. Tratado de Neurologia de Merrit, Rio de Janeiro: Guanabara Koogan, 1999, 858p.

3.Delisa JA. Tratado de Medicina de Reablitação, Princípios e Prática, São Paulo: Manole, 2002, 980p.

4.Saccheli T, Accacio LMP, Radl ALM. Fisioterapia Aquática, São Paulo: Manole, 2007, 236p.

5.Campion MR. Hidroterapia - Princípios e prática, São Paulo: Manole, 2000, 306p.

6.Lutz ER. Watsu-aquatic bodywork. Beginnings 1999;19:9-11.

7.Noh DK, Lim JY, Shin HI, Paik NJ. The effect of aquatic therapy on postural balance and muscle strength in stroke survivors--a randomized controlled pilot trial. Clin Rehabil 2008;22:966-76.

8.Hall J, Swinkels A, Briddon J, McCabe CS. Does aquatic exercise relieve pain in adults with neurologic or musculoskeletal disease? A systematic review and meta-analysis of randomized controlled trials. Arch Phys Med Rehabil 2008;89:873-83.

9.Waller B, Lambeck J, Daly D. Therapeutic aquatic exercise in the treatment of low back pain: a systematic review. Clin Rehabil 2009;23:3-14.

10.Dziedzic K, Jordan JL, Foster NE. Land- and water-based exercise therapies for musculoskeletal conditions. Best Pract Res Clin Rheumatol 2008;22:407-18. 